Ciencia y Sociedad, Vol. 44, No. 2, abril-junio, 2019 •ISSN: 0378-7680 • ISSN: 2613-8751 (en línea)

DOI: https://doi.org/10.22206/cys.2019.v44i2.pp55-77

\title{
LA DEFENSA DEL HUMANISMO EN EL LIBRO NARRATIVIDAD DEL SABER HUMANÍSTICO DE MANUEL MATOS MOQUETE
}

\section{The humanism defense in the book humanistic knowledge narrative by Manuel Matos Moquete}

\section{Julio Minaya Santos}

Profesor Titular de la Universidad Autónoma de Santo Domingo, República Dominicana

Correo-e: jminaya70@uasd.edu.do ORCID: 0000-0001-8915-6308

Recibido: 4/4/2019 • Aprobado: 8/5/2019

Cómo citar: Minaya Santos, J. (2019). La defensa del humanismo en el libro Narratividad del saber humanístico de Manuel Matos Moquete. Ciencia y Sociedad, 44(2), 55-77. Doi: https://doi.org/10.22206/cys.2019.v44i2.pp55-77

Resumen

En la actualidad, el relato humanístico clásico ha sido desafiado por nuevos formatos teóricos y construcciones utópicas, surgidos en el seno de las ciencias biológicas, la cibernética y la inteligencia artificial. Estos saberes propugnan por el diseño de un nuevo ser humano, proyecto a favor del cual accionan posthumanistas y transhumanistas. En tal sentido, los valores en que se fundamentaban tanto el humanismo como las humanidades han sido cuestionados. Tal situación ha generado la emergencia de importantes discursos en el seno de diversas disciplinas. Uno de ellos es el que ha construido Manuel Matos Moquete en su libro Narratividad del saber humanistico. El presente trabajo constituye un esfuerzo por adentrarse en los planteamientos centrales del autor, cuya obra intenta dotar de sentido temas cruciales de nuestra época.

Palabras clave: Manuel Matos Moquete; relato humanístico; cibernética; inteligencia artificial; posthumanismo y transhumanismo.

\begin{abstract}
Nowadays the classic humanistic narrative has been challenged by new theoretical formats and idealistics constructs emerged from the depth of the biological sciences, cybernetics, and artificial intelligence. These new approaches promote the design of a new human being, which is a project that posthumanism and transhumanism's enthusiasts advocate for. In that sense, the beliefs humanism as well as the humanities have based on have been challenged. Such a situation has propelled the creation of emergent approaches in the depth of many diverse disciplines. One of these approaches is the one created by Manuel Matos Moquete in his book Humanistic Knowledge Narrative. This publication is an attempt to go deeper into the author's central ideas, which tries to add sense to vital topics of our times.
\end{abstract}

Keywords: Manuel Matos Moquete; humanistic narrative; cybernetics; artificial intelligence; posthumanism and transhumanism. 


\section{Introducción}

En su actualizada obra Narratividad del saber humanistico (2018) Manuel Matos Moquete declara agotado el relato humanístico clásico. Al mismo tiempo, realiza un distanciamiento crítico respecto de diversos autores y doctrinas que, tomando como fundamento los extraordinarios avances registrados en materia de bioingeniería, tecnología médica, cibernética e inteligencia artificial, vienen proclamando el fin del Homo sapiens como especie.

Para contrarrestar las tesis principales de los llamados posthumanistas, basadas en el postulado de que el ser humano como tal ya no existe, el autor emprende un minucioso recorrido histórico al hilo de la corriente humanística, la cual inicia su andar en los escritos de Platón, sigue con los retóricos romanos, se fortalece e impulsa durante el Renacimiento y llega a su clímax con la Ilustración. Tal estrategia le permite hacer acopio del extenso aparato conceptual logrado por el despliegue de la tradición humanística, aquilatando su verdadera significación. Para lograrlo, le ha bastado la amplia formación profesional e intelectual dentro de un amplio espectro de disciplinas estudiadas en la Universidad de París viII, nutrida notablemente por el esfuerzo autodidáctico que le caracteriza.

Doctor en literatura, especialista en análisis del discurso y lector asiduo de filosofía, pedagogía, historia, política, ciencia, Matos Moquete es poseedor de un amplio bagaje teórico, gracias al cual ha podido refinar las diversas aristas del saber humanístico, reflexionando holgadamente sobre su genealogía, desarrollo, crisis y debate actuales.

Se confiesa partidario de un humanismo abierto y plural, "sin fronteras", capaz de acoplarse a los diversos estadios de desarrollo de la ciencia y la tecnología. Por eso, aunque declara agotado el humanismo clásico en muchos aspectos, capta aún su presencia en el proyecto posthumanista o transhumanista. ¿Se procura un ser humano que duplique o triplique su capacidad de vivir, a partir de las llamadas células embrionarias? ¿Se pretende lograr un ser humano con vocación de perpetuar su existencia biológica? Tales aspiraciones, por extraordinarias que parezcan, no resultan completamente ajenas al plexo utópico construido por el humanismo renacentista, pues ya aquí se postulaba la consecución de un ser humano en búsqueda constante de la perfección. De ello dan pruebas las variantes utópicas que emergieron durante el Renacimiento.

Pero ¿qué mueve a Matos Moquete a hurgar sobre la producción teórica del humanismo, una de las categorías centrales de la racionalidad occidental? El motivo fundamental consiste en dotar de sentido la vida humana en las circunstancias presentes; procurar hacer inteligible el mundo que hemos construido los seres humanos en los últimos cinco siglos, pero muy especialmente en las últimas décadas, durante las cuales hemos sido testigo del desplome súbito de viejos paradigmas y la emergencia de otros, como se aprecia claramente en este escrito esencial de nuestro Premio Nacional de Literatura 2019.

El presente trabajo no se propone abarcar en toda su extensión el libro Narratividad del saber humanistico; se contrae más bien a los primeros tres capítulos. La razón es que las primeras secciones de esta obra constituyen su columna vertebral; en ellas el autor logra, como buen ensayista, la problematización y profundización de la temática que le ocupa y preocupa, argumentando puntos de vista personales de gran calado sobre la cuestión. Por supuesto, lo anterior no significa que los siete capítulos restantes carezcan de interés o relevancia, o que no guarden conexión con la temática central, pues como bien puede advertirse, cada uno de estos apartados guardan estrecha conexión con el tema principal.

\section{Narratividad y "humanismo sin fronteras": la apuesta de Manuel Matos Moquete}

"Narratividad, discurso y conocimiento" es el nombre del primer capítulo del libro aquí abordado. Su lectura atenta hace inteligible las implicaciones semánticas y la importancia del concepto de 
narración; permite entender por qué el humanismo constituye una función narrativa y las razones para no limitar lo narrativo exclusivamente al cuento y la novela, dado que tal función está presente en la totalidad de los saberes, trátese de filosofía, arte, religión o de ciencia y tecnología, pudiendo incluirse también el discurso sobre lo virtual o digital.

Importa destacar aquí un elemento puesto de relieve por el autor al referirse a lo implicado en el concepto de narración: que no se está ante un género, sino frente a:

una gran función que abarca diversos géneros y modos de comunicación, desde los más antiguos e informales (...) como el mito, la leyenda y la conversación, hasta los más formales y modernos como la literatura escrita, la relación histórica y el informe administrativo, científico y tecnológico de las grandes instituciones y funciones de la vida moderna (Matos Moquete, 2018, p. 23).

El ensayista reconoce que esta manera de concebir lo narrativo de un modo amplio y natural, como el lenguaje mismo, genera la sospecha de mucha gente, especialmente entre los cultivadores de la ciencia quienes ven al relato muy alejado del quehacer cognitivo. Son muchos los autores que ponen de manifiesto el carácter narrativo de las teorías científicas, al tratarse de construcciones humanas en cuyo seno también se gestan y alimentan mitos. "Porque no es posible estatuir ciencias destituidas de sujetos; purificada de los afectos, iras, marcas inconscientes, ideologías o valores éticos de los cuales se nutren -queramos o no- estudiantes, profesores e investigadores de todos los tiempos y lugares" (Xavier de Almeida (2009), citado por Matos Moquete, 2018, p. 20).

Nuestro humanista asume la temporalidad como un rasgo esencial de la función narrativa. Considera el amor como un relato, lo mismo que cualquier situación humana, como el odio, la vida, la muerte, el infortunio. De este modo Matos Moquete (2018) sostiene: "La única condición sería que pudiera reconocerse como un proceso o programa de actos o acciones que discurren temporalmente" (p. 13).

En la anterior consideración el autor coincide con Paul Ricoeur, del cual extrae planteamientos básicos: "Todo lo que se cuenta sucede en el tiempo, arraiga en el mismo, se desarrolla temporalmente; y lo que se desarrolla en el tiempo puede narrarse" (Ricoeur, 2000 citado por Matos Moquete, 2018, p. 13). Estas ideas permiten aquilatar la naturaleza peculiar de la función narrativa, cuya presencia se advierte en tantas disciplinas o formas discursivas, lo cual ha llevado a M. L. Ryan (2004) a considerar la narratividad como "una estructura semántica universal".

Lo que antecede conduce a Matos Moquete (2018) a postular una de las tesis capitales de su obra: que la narratividad ha de concebirse "como la expresión de un humanismo sin fronteras", puesto que, desde el punto de vista lingüístico, dentro del humanismo y las humanidades "no existen espacios cerrados ni vacíos, dondequiera hay significaciones"; concluyendo el autor "que el relato es común a todos los conocimientos, empleándose así en las ciencias como en la vida cotidiana" (p. 23).

El pensador advierte sobre el error en que se incurre al pretender trazar fronteras entre las humanidades, las ciencias y la tecnología. Sobre tales límites Matos Moquete (2018) aclara: "sólo son pertinentes en abstracto y en el ámbito del aprendizaje escolar, pero difícilmente pueden establecerse en el discurso y en la práctica comunicativa" (p. 25). De hecho, abundan autores dentro de la corriente humanística que reflejaron en sus obras la diversidad de saberes existentes, siendo a la vez matemáticos, científicos, pensadores, artistas. Frente a una cultura científica y académica cada vez más especializada, en que los diversos saberes se convierten en departamentos estancos, nuestro autor alza su voz disidente: 
No hay discontinuidad entre las humanidades, las ciencias y las tecnologías. Todo lo contrario: hay continuidad y complicidad. Todos salen del mismo tronco del sentir y el pensar humanos, aunque se ramifiquen por diversas e infinitas venas.

Y en todas, aunque sean expresiones distintas, obra en su producción y comunicación un modelo discursivo común: el relato (Matos Moquete, 2018, p. 24).

Por supuesto, juzgados dentro del marco de una cultura académica dominada por un cientificismo desenfocado, los planteamientos anteriores bien pudieran catalogarse de erróneos, lo cual tiene solo una explicación: la imposibilidad de captar la unidad compleja de todo cuanto existe. Para nuestro autor, las fronteras entre los diversos dominios cognitivos solo tienen pertinencia en abstracto y como estrategia en el ámbito del aprendizaje escolar.

De acuerdo al intelectual crítico, el "humanismo sin fronteras" es portador de un mensaje alentador y pro humanizador, en tanto rechaza los causes estrechos de un humanismo adocenado e instrumentalizado, donde habitan sin estorbo el fanatismo y el dogmatismo. Matos Moquete (2018) aclara: "No hay un dado o un acabado. No existe un mundo concluido y cerrado; difícil es decir "Aquí hay, allá no hay". Ese no es el asunto. Sólo existen las palabras en situación" (p. 23).

El "humanismo sin fronteras" aquí planteado, propiciador de apertura y búsqueda de sentido, se convierte en perspectiva clave para conservar las expresiones espirituales de la sociedad, pilares del humanismo. Pero, ¿qué ocurriría si las denominadas "Creaciones de la cultura espiritual", como el lenguaje, la ciencia, el mito, el arte y la religión, lejos de ser estimuladas y desarrolladas, fueran apocadas y deprimidas? En opinión de Matos Moquete estaríamos ante el fracaso del proyecto humano, lo cual preocupa enormemente al autor, como veremos en adelante.

\section{El humanismo: permanencia y cambio a través del devenir histórico}

En el capítulo 2, Matos Moquete se enfrenta a un tema crucial: "Permanencia y cambio del humanismo". Inicia declarando dos rasgos sobresalientes del relato humanístico, a saber: que encierra un significado complejo y que constituye "un saber fundamental". Considera que quizá se esté ante "el tópico más importante de la cultura occidental"; no de la racionalidad oriental, pues el pensar y el vivir en Oriente se nutren de relatos diferentes.

De entrada, en este capítulo el semiólogo nos informa de algo crucial: que la narratividad humanística emerge como un gran ideologema, esto es, un discurso cargado de valoraciones, visiones e ideas sobre lo que somos y lo que queremos ser. Pero, además, introduce un ingrediente esencial y potencialmente polémico: el humanismo es etnocentrista. Tal aserto no ha de extrañar, pues con el humanismo estamos situados ante un engendro teórico de matriz europea, el cual, como se ha referido, emerge vinculado inexorablemente a una Weltanschauung ${ }^{l}$.

El humanismo clásico tiene una concepción eurocéntrica desde su propio surgimiento; incluso,

\footnotetext{
1. Vocablo alemán que recoge el sentido y significado de expresiones como cosmovisión o concepción del mundo. Podría traducirse como "intuición del mundo". Karl Jaspers ha escrito sobre una psicología de las concepciones del mundo, distinguiendo entre imagen espacio-sensorial del mundo, imagen psíquico-cultural e imagen metafísica. Wilhelm Dilthey dio notable impulso al estudio de las concepciones del mundo, elaborando una teoría al respecto o Weltanschauungslehre. Dilthey da mucha importancia al factor histórico, sugiriendo que las concepciones del mundo pueden cambiar en el tiempo, pero sin dejar de subrayar los llamados "aspectos metafísicos", que explican la permanencia de algunos rasgos esenciales. Cabe señalar que, en lo que respecta al tratamiento teórico dispensado por Manuel Matos Moquete al tópico del humanismo, este lo vincula a esta categoría filosófica (empleada por él como "visión del mundo", la cual tiene un carácter muy general y complejo por la multiplicidad de elementos que encierra. También se nota otra vinculación: el sostener que el relato humanístico ha sufrido transformaciones a través del tiempo, pero a la vez, ha conservado algunos de sus componentes esenciales.
} 
como apunta Matos Moquete, a veces solo abarcaba algunos pocos países de Europa. Por supuesto, la visión supremacista de dicha categoría excluía a los pueblos asiáticos, africanos o latinoamericanos. No obstante, bien pensado lo anterior, ¿no encierra esto una paradoja?, ¿no tendría que ver el humanismo -en cuanto concepto- con todos los seres humanos, propiciando una valoración justa, sin discriminación por motivos étnicos, culturales o religiosos? Así debiera ser, pero no debe olvidarse lo reiterado por el autor: el humanismo es un ideologema.

Matos Moquete no tiene reparos en asumir el paradigma humanístico, aun reconociendo sus implicaciones etnocéntricas. Así, el mismo autor (2018) argumenta:

Si asumimos aquí la defensa del humanismo, lo hacemos conscientes de las implicaciones etnocéntricas de ese concepto, pero también de que es un legado cuya permanencia ha sido universalmente posible porque en el tiempo se ha ido construyendo en la diversidad, con los aportes de diferentes culturas. (p. 28).

¿No ha cometido un error nuestro autor al asumir el relato humanístico a pesar de dicha postura etnocentrista? En modo alguno, pues lo concibe como un relato que se construye históricamente $y$, por tanto, nunca estará exento de valoraciones o intereses ideológicos. Matos Moquete aclara la cuestión del siguiente modo: "como ideologema el humanismo es un signo portador de ideología: se sitúa en un discurso que implica propósitos, referencias, conceptualizaciones, visiones y tomas de posiciones sobre determinados temas, como el ser humano, el cosmos y la divinidad". (p. 27).

Importa aquí clarificar la significación del término ideologema. El autor se encarga de ello en otra de sus obras. "En la tradición filosófica y literaria se conocen tópicos universales como el amor, la vida y la muerte, que a su vez son grandes ideologemas: expresan grandes creencias del ser humano" (Matos Moquete, 2009, p. 17). Hemos notado el manejo reiterado que hace nuestro filólogo en torno al vocablo humanismo como ideologema. La palabra pueblo es claro ejemplo de ideologema. Matos Moquete (2009) explica: "En la democracia dominicana el tópico pueblo es el ideologema principal del discurso político, a partir del cual deberán analizarse y evaluarse los demás tópicos y el lenguaje mismo. Ese tópico presupone a los demás por ser a la vez contenido y continente, esencia y forma del discurso democrático" (p. 31).

Así pues, como cualquier otro concepto o categoría, el humanismo está condicionado por diversos componentes o factores que importa tener en cuenta, por consiguiente, no debe emplearse como si encerrara esquemas mentales puros; por el contrario, conlleva modelos de historias y de situaciones que implican propuestas ideológicas, tramas, roles, personajes, entre otros factores o elementos, como atinadamente nos explica el autor.

Estas reflexiones son de enorme relevancia debido a que, como se argumenta en la obra, el humanismo es una expresión ideológica, artística y filosófica de sectores burgueses, que asumieron concepciones propias para desmarcarse de la cosmovisión abrazadas por las clases dominantes feudales durante el Medioevo, centrada en el pensamiento escolástico. $\mathrm{Ha}$ de entenderse que los nuevos sectores sociales que sintonizan con la corriente humanista y la impulsan, ya no pueden continuar sustentando el teocentrismo medieval, en cuanto son portadores de aspiraciones e intereses muy distintos, desde los económicos hasta los filosóficos.

De hecho, hay un rasgo o característica general que distingue e identifica a la sociedad emergente de corte moderno, se trata del antropocentrismo: el hombre se visualiza como centro de todo cuanto existe. Tal característica del humanismo se ha mantenido a través de siglos como señal distintiva de la narración humanística; tan importante que, de su vigencia o no, pende la existencia misma del movimiento o doctrina humanista. Nuestro autor tiene plena conciencia de ello al declarar: 
Que nadie se llame a engaños: la humanidad es una construcción forjada mediante una conceptualización antropocéntrica milenaria. El homo sapiens fue colocado en el centro del universo. En esa construcción, la antropología filosófica grecolatina y el humanismo de los siglos XIV AL XVI han jugado un papel determinante (Matos Moquete, 2018, p. 45).

Tal concepción antropocéntrica centra y da soporte teórico al relato aquí dilucidado por Manuel Matos Moquete. Tras el derrumbe del Medioevo sobrevino la lucha entre dos clases o segmentos sociales, los cuales, aparte de defender intereses de tipo económico y social contrapuestos, se aferran a lo que consideran más importante desde una óptica intelectual o espiritual. En efecto, las clases feudales - de intensa vocación católica- enfatizaban "el más allá", representado en Dios; en cambio, los mercantilistas, con una nueva imagen del mundo acomodada al naciente saber científico, artístico y filosófico moderno -embrión del capitalismo o sociedad moderna-, se interesarán por "el más acá". En ese "más acá" va prevaleciendo cada vez más el ser humano, no una entidad sobrenatural.

Pero hay otra cuestión que merece ser subrayada: el humanismo y el mercantilismo surgen juntos en el seno de la sociedad moderna. La supremacía del ser humano pregonada por el movimiento humanista va de la mano del afán de lucro, de la iniciativa individual. Se exige libertad para el accionar del hombre, no solo en sentido comercial, sino en todos los aspectos de la vida. Estas cuestiones guardan estrecha relación con dos pilares importantes del relato humanístico, que Manuel Matos Moquete coloca en un sitial de preponderancia. Nos referimos a los tópicos de libertad y seguridad.

Deviene en una necesidad detenerse un momento y aprovechar lo anterior para lograr una mejor intelección del humanismo como ideologema; ello permite entender las limitaciones e incongruencias que acechan y afectan al relato humanístico a lo largo de su despliegue histórico.
Cuando los españoles pisan tierra de este lado del Atlántico el humanismo experimentaba una etapa de gestación. En gran medida, la empresa colombina constituye una empresa renacentista en un contexto mercantilista. Colón procede de Génova y su imagen del mundo remite fundamentalmente a los nuevos saberes y aspiraciones impulsados por la burguesía mercantilista; en su proyecto están involucrados mercaderes del Mediterráneo español. Hay pues una doble procedencia entre los que acompañan al Almirante: los que responden al nuevo paradigma mercantilista y los que aún viven en el retardado feudalismo español.

Lo anterior permite explicar lo ocurrido en el seno de la sociedad taína, tras la llegada de los españoles en 1492. Los estamentos dominantes dentro del conjunto de colonizadores respondían a los esquemas del viejo orden feudal, fundamentaban sus vidas e ideales en el pensamiento tomista-aristotélico, lo cual implicaba, por una parte, obedecer al Papa y propugnar por evangelizar a los taínos; por la otra, seguir las orientaciones derivadas de una empresa mercantilista (sedienta de metales preciosos), que al surgir en el seno del Renacimiento europeo, se sirve de las nuevas técnicas de navegación y de los recientes conocimientos geográficos y astronómicos, sin los cuales nadie se aventuraba a atravesar el Atlántico.

Para los colonizadores españoles los taínos de las Antillas sustituyen a los antiguos bárbaros. No son personas, significan más bien homúnculos, motivo por el cual no sienten escrúpulos cuando los exponen a morir en las minas o durante las guerras llamadas Justas. Sin embargo, no todos los conquistadores y colonizadores piensan y actúan de igual manera: existe un sector exclusivo formado por personas cultas que han recibido las enseñanzas de los últimos humanistas: Erasmo de Rotterdam y Tomás Moro²,

2. En la época renacentista, cuando la economía mercantil atraviesa por un momento de auge y el afán de lucro se impone en los segmentos más dinámicos y privilegiados, la prédica humanista de Moro se deja escuchar con intensidad: "Estimo que 
en las universidades de Salamanca, Valladolid y Alcalá de Henares. Nos referimos a Pedro de Córdoba, Antón de Montesinos y Bartolomé de las Casas.

Estos son humanistas coherentes con sus propias ideologías y aspiraciones: valoran al otro, al diferente, concibiéndolo igual al caucásico, al europeo. En efecto, son portadores, como los de demás, de una ideología; pero aquí conlleva una visión muy distinta en torno a lo que es ser humano, la que colide con el etnocentrismo enquistado dentro de la corriente humanista construida en Europa. Por lo tanto, los frailes dominicos no tienen reparos en encabezar la defensa de los taínos en las Antillas. Aquí el ideologema encerrado en la concepción humanística se apertura positivamente en favor de la otredad, permitiendo el reconocimiento del otro que, aunque diferente, al fin y al cabo, constituye un ser humano digno y valioso.

Por lo visto, es imposible despojar la narración humanística de su significado como ideologema, lo mismo que de su naturaleza utópica. Falta por dilucidar y profundizar aún más ambas cuestiones.

\section{Agotamiento del relato humanístico y su signi- ficación como ideologema ${ }^{3}$}

Al hilo de los planteamientos de esta importante obra de Manuel Matos Moquete, y a los fines de tornar inteligible sus ideas y preocupaciones frente al relato humanístico, me aventuro a plantear que lo sucedido en la actualidad no es totalmente ajeno a lo

dondequiera que exista la propiedad privada y se mida todo por el dinero, será difícil lograr que el Estado obre justa y acertadamente, a no ser que piense que es obrar con justicia el permitir que lo mejor vaya a parar a manos de los peores, y que se vive felizmente allí donde todo se haya repartido entre unos pocos que, mientras los demás perecen de miseria, disfrutan de la mayor prosperidad" (Moro, 1956, p. 35).

3. Para Manuel Matos Moquete (2009), el vocablo ideologema hace referencia a estructuras conceptuales complejas que están presentes en las palabras, razón por la cual no debemos ver las palabras simplemente como listas de atributos (p. 16). ocurrido durante el momento inicial de la sociedad moderna: me refiero a la tensión reinante entre el afán de lucro y los valores humanísticos asumidos. Tal conflicto, en mi opinión, va a caracterizar hasta hoy el devenir histórico de la sociedad occidental a partir del periodo renacentista. Nuestro autor lo visualiza como la contradicción entre el "progreso material y el progreso humanístico". Tensión advertida ya por Eugenio María de Hostos hacia finales de siglo XIx, al referir el estado crítico que se vivía en Santo Domingo para aquxel entonces. Hostos (1939) asegura que se atravesaba por una "Crisis sistemática (...) nacida de un progreso mal encaminado (...). ¡Qué importa a un país que el capital aumente, si no aumenta el bien de todos!" (p. 172).

El pedagogo y filósofo puertorriqueño contraponía progreso material a progreso moral. Con respecto a ello visualizaba incongruencias en el tipo de sociedad que la modernidad ha pretendido establecer como modelo en Occidente. Así, Hostos (1939) argumenta: "La divergencia entre el llamado progreso material y el progreso moral es tan manifiesta, que tiene motivos la razón para dudar de la realidad de la civilización contemporánea” (p. 105).

En su libro, Matos Moquete, muy preocupado -y en ocasiones con dejos de angustia-, ahonda en la problemática del humanismo en nuestra época. Palpa cómo dos de sus narrativas fundamentales: libertad y seguridad, se tornan cada vez más inalcanzables para la humanidad. A esto habría que agregar la identidad rota o fragmentaria del sujeto, como resultado de la trashumancia característica de las personas en la era globalizada y marginalizada, sin asentamientos fijos y en constante búsqueda por mejores condiciones de vida.

El autor presenta el recorrido lógico-histórico de la corriente humanista a través de varios siglos; nota que el humanismo clásico deviene agotado de cara a nuestra realidad; observa que a partir de la Segunda Guerra Mundial se desata un complejo causal llamado a imprimir un giro a la vida política, 
social e intelectual, provocando transformaciones profundas dentro de los paradigmas existentes.

Ha de señalarse que lo sucedido en Europa, con Hitler y Stalin a la cabeza, dejó a la humanidad en estado de completa perplejidad. Se revisaron seriamente los tópicos de progreso, libertad, igualdad, razón y orden proclamados por los ilustrados. Una época de grandes transformaciones se presencia a partir de 1960: "de los negros por sus derechos sociales y étnicos, de los llamados "hippies" por sus reivindicaciones propias (...), de los movimientos feministas por los derechos de la mujer" (Matos Moquete, 2018, p. 35). Se registra también un rápido desarrollo de las ciencias del lenguaje, de las ciencias sociales, pero son adelantos que, si bien quedaron antes integrados al programa propiciado por el humanismo y los humanistas, ahora empero lo debilitan sensiblemente, y se asiste en las últimas décadas del siglo xx al cierre de un ciclo dentro del saber humanístico.

El proceso de desgaste fue tan intenso que, como muestra el autor, propuestas humanísticas que perduraron por siglos, ahora devienen formalizadas y confinadas dentro de un academicismo estéril, convirtiéndose en saberes cosificados, sin ideales, sin impulso renovador vital. En tal perspectiva argumenta que:

Corrientes como el estructuralismo y el funcionalismo, que se impusieron en las humanidades y en las ciencias sociales, específicamente en las ciencias del lenguaje, castraron las posibilidades de construir un relato humanístico significativo y trascendente. El instrumentalismo y el utilitarismo en la política y en las artes, en general en la cultura, limitaron los alcances de las expectativas a lo inmediato y lo conveniente, dejando de lado las utopías propias del pensamiento humanístico (Matos Moquete, 2018, p. 36).

Con cierta nostalgia, el autor confiesa que antes había confianza en la razón, en las ideas, los valores, las ciencias y las tecnologías, y cada uno de estos elementos contribuían con el incremento del bienestar humano. Por más avances que se registraran nunca se ponía en tela de juicio que el hombre ocupaba el centro del universo.

Junto a lo anterior, nuestro pensador constata el modo en que vienen muriendo las ideologías. Pone el ejemplo de cómo ha menguado la idea de progreso, sumándose a ello la muerte de las utopías que desde Platón significaban aspectos medulares para la orientación y sustentación de la vida individual y colectiva. Deplora que ya hoy no se habla de utopía ni se enaltecen los valores consubstanciales a la persona humana. Todo esto arroja como consecuencia que en la actualidad esté cada vez más en desuso la palabra humanista; se prefieren otras palabras o denominaciones como: lingüista, escritor, ensayista, crítico literario, filósofo, sociólogo.

Para Matos Moquete, Habermas y Chomsky debieran ser considerados grandes humanistas. No ocurre. La causa principal -en opinión del pensador- radica en la hiperespecialización prevaleciente. Se ha caído en los brazos de la división social del trabajo. Tales planteamientos encierran una enorme significación. En mi concepto, la crisis que ha venido sacudiendo al paradigma humanístico podría explicarse a partir del deterioro y desprestigio que han padecido algunas de sus categorías centrales y fundantes, ya referidas por nuestro semiólogo: progreso, razón, libertad, seguridad, lo cual es inevitable. Tal situación fue ya anticipada, aun sea parcialmente, hacia finales del siglo XIX por pensadores como Nietzsche o Dostoevsky; y por Pedro Francisco Bonó en República Dominicana.

El libro de Matos Moquete incita a pensar profunda y detenidamente acerca del agotamiento que acusa la narración humanística.

En el presente trabajo se plantea la hipótesis siguiente: en cuanto concepto, el humanismo clásico tuvo que experimentar cierto proceso de desgaste para flexibilizarse y extenderse semánticamente más 
allá del ser humano blanco, más allá del ser humano varón, más allá del Estado colonialista europeo o estadounidense. En otras palabras: la concepción etnocéntrica, androcentrista y eurocentrista, encerrada en la categoría humanismo, debió sufrir cierto resquebrajamiento a nivel de su estructura interna, para, como estructura conceptual, dilatarse hasta poder incluir o comprender la totalidad de los seres humanos, y no únicamente a una parte de estos.

Baste señalar que gran parte de las revoluciones inspiradas en los filósofos liberales e ilustrados o humanistas clásicos (inglesa, francesa, estadounidense) no promulgaron en sus constituciones políticas la igualdad de derechos para hombres blancos y negros, tampoco para las mujeres. Los desfavorecidos acusaron estatus de inferioridad y carencia de derechos civiles y políticos frente a los hombres blancos. Guerras e intensas luchas civiles en Estados Unidos (Abraham Lincoln y Marthin Luther King como protagonistas), así como grandes enfrentamientos en África del Sur (liderados por Mandela en oposición al Apartheid) tuvieron que adoptarse para lograr a la postre el reconocimiento de los derechos de todas las personas, sin importar el color de su piel ni su género. De ahí la trascendencia histórica de tales acontecimientos.

Es un hecho cierto que muchos renacentistas, racionalistas, ilustrados, positivistas y marxistas, fueron exponentes eximios del humanismo, pero no puede negarse que entre sus filas abundaron autores racistas, ardientes militantes de la supremacía blanca. Para lograr que muchas colonias africanas, asiáticas y latinoamericanas alcanzaran su independencia, gran parte de los humanistas fueron colonialistas y restaron capacidad a los hijos de las colonias para el ejercicio del autogobierno, el humanismo debió atenuarse y dilatarse, para que se asimilara el hecho de que las colonias podían también proclamar Estados autónomos. Y, por último, para que la mujer pudiera lograr derechos igualitarios frente al hombre. Dado que los humanistas fueron en su inmensa mayoría androcentristas, debió también abrirse una grieta al interior del concepto humanístico. Estas diversas modificaciones devinieron en una necesidad ineludible, pues sin ellas hoy los negros y las mujeres no pudieran disfrutar de los derechos que las legislaciones les confieren. De igual manera, los diversos Estados nacionales surgidos en la periferia de las potencias capitalistas centrales, no habrían conquistado su derecho a existir, aun con todas las limitaciones con que han operado y operan.

Lo anterior no significa que algunos representantes del Renacimiento, de la Ilustración o del Romanticismo, etc. no apoyaran las causas de los negros, de las mujeres o de la emancipación de los pueblos resultantes de las antiguas colonias. La historia de la filosofía, del derecho y de la política registra casos excepcionales. Por ejemplo, hubo casos de algunos ilustrados que plantearon tempranamente el tema de la igualdad entre mujeres y hombres. Pero todo esto no viene más que a confirmar el postulado de Manuel Matos Moquete, en el sentido de que el humanismo constituye un ideologema. De suerte que pueden encontrarse diversos sectores o tendencias dentro de la vertiente humanística que alberguen aspiraciones y cosmovisiones distintas, y a veces hasta contrapuestas. Por tanto, no ha de sorprender que hacia 1789 , en el marco de la Revolución Francesa, los derechos proclamados y reconocidos fueran los del "Hombre y del Ciudadano", excluyéndose por completo a la mujer ${ }^{4}$.

A partir de los planteamientos referidos, es importante resaltar que en el humanismo no estamos ante un concepto puro, unívoco o sin fisura. $\mathrm{Y}$ nuestro autor está consciente de ello al reivindicar

4. Precisamente, indignada porque no abarcaba o incluía también al sector femenino, Olympe de Gouges (cuyo verdadero nombre era Marie Gouze), redactó la "Declaración de los Derechos de la Mujer y de la Ciudadana” (1791), con 17 artículos y un epílogo. En su primer artículo se lee: "La mujer nace libre y permanece igual al hombre en derechos. Las distinciones sociales sólo pueden estar fundadas en la utilidad común". La declarante fue juzgada sumariamente y guillotinada en 1793 , por defender los postulados de los Girondinos. 
su significado como ideologema. En igual perspectiva, Guadarrama (2012) aclara que:

se caracteriza en lo fundamental por propuestas que sitúan al hombre como valor principal en todo lo existente y (...) subordina toda actividad a propiciarle mejores condiciones de vida material y espiritual, de manera tal que puede desplegar sus potencialidades siempre limitadas históricamente (p. 24).

El filósofo cubano reconoce que en el humanismo no se está ante una corriente filosófica o cultural homogénea y sí ante un movimiento que ha confrontado limitaciones históricas en su devenir. Por lo que Guadarrama (2012) plantea:

La toma de conciencia de estas limitaciones no las ve como obstáculo insalvable, sino en pivote que moviliza los elementos para que el hombre siempre sea concebido como fin y nunca como medio. Sus propuestas están dirigidas a reafirmar en el mundo, a ofrecerles mayores grados de libertad, y a debilitar todas las fuerzas que de algún modo pueden alienarlo (Guadarrama, 2012, p. 24).

Tanto Manuel Matos Moquete como Pablo Guadarrama abrigan concepciones realistas y optimistasacercadel relato humanístico. En realidad, los autores humanistas desde el Renacimiento hasta nuestros días abrieron nuevas compuertas teóricas para la valorización de los seres humanos, en ocasiones de modo lento y hasta contradictorio, pues tales valoraciones no siempre tomaron en cuenta la totalidad de los seres humanos. Prueba de ello es el etnocentrismo reconocido por Matos Moquete al interior de la narración humanística, lo que no debe sorprender a nadie, pues el mismo autor refiere los condicionamientos que afectan al paradigma humanístico desde su emergencia hasta nuestros días.

En realidad, ha de reconocerse que de parte de los humanistas clásicos hemos recibido como legado excepcionales aportes históricos que, traducidos a códigos jurídicos, conceptos y teorías, resultan imprescindibles para dar cuenta de cómo han sido valorizado históricamente los seres humanos. Entre dichos aportes tenemos categorías y expresiones como "Dignidad Humana" y "Derechos Humanos". Por lo que, si bien, como se ha indicado, acusó múltiples limitaciones e incongruencias, lo cierto es que el humanismo motivó y fundamentó racionalmente avances antropológicos de primer rango, ampliando con sus contribuciones la cobertura de libertades y derechos en favor de determinados segmentos sociales e incluso naciones, previamente excluidos y oprimidos.

\section{La crisis del relato humanístico corre pareja a la crisis de sus categorías centrales}

El humanismo ha sido etnocentrista, eurocentrista, androcéntrico y antropocéntrico. Pero ¿no lo han sido también las vertientes teóricas o escuelas de pensamiento que lo han gestado, nutrido y divulgado? Hacemos referencia al Racionalismo, a la Ilustración, al Romanticismo, y a categorías centrales como progreso, razón, libertad, seguridad. Unas y otras quedaron en entredicho luego de la experiencia nefasta de la Segunda Guerra Mundial que, entre otras tragedias, provocó el holocausto judío y la explosión de las bombas atómicas.

Hoy se asiste a una crisis real del relato humanístico, como bien lo reconoce Manuel Matos Moquete. En mi concepto, esta crisis se debe a que dicha corriente nace simultáneamente con la modernidad o capitalismo en su fase mercantilista, por lo cual tanto dicha modernidad, como la narración humanística que le es complementaria a nivel teórico, exhiben importantes momentos de crisis en su desarrollo lógico-histórico. De forma parecida a la decadencia por la que ha atravesado una idea-fuerza de la modernidad, del humanismo y del capitalismo: la idea o dogma de progreso. Como bien lo argumenta Matos Moquete (2018): 
La idea de progreso humano fue menguando, a pesar de los avances en la solución de los problemas materiales, de educación y de salud. A pesar del avance de las ciencias y la tecnología.

He ahí la gran paradoja: más progreso, menos progreso humano. Y la misma palabra progreso hubo de ser revisada y redefinida (pp. 38, 39).

De hecho, la UNESCO, consciente del desprestigio y confusión en torno al tópico progreso, ha tenido que matizar dicha categoría, planteando la necesidad de un progreso social llamado a ser inclusivo. En República Dominicana se tiene una crítica de la doctrina de progreso desde la segunda mitad del siglo XIx:

Esta teoría echada a los cuatro vientos por las grandes naciones civilizadas, repletas de población, de capital, de ciencia, experiencia, actividad y demás accesorios para aplicarlas con energía y con fruto a la explotación de hombres y de cosas, es uno de los males que afligen al mundo en la actualidad (Bonó, 1980, pp. 413, 414).

Dentro de este contexto histórico y teórico habría que visualizar al humanismo vinculado a una serie de conceptos fundamentales o de idea-fuerzas que han caracterizado a la racionalidad occidental. Sería imposible su dilucidación teórica abstraído de una serie de categorías centrales. Matos Moquete (2018) advierte en torno a la narración humanística:

Es un cuerpo de ideas y valores que llenan de sentido al ser humano. Propongamos algunos de los conceptos clave en la historia de ese movimiento: la idea de la dignidad humana, de la razón, del progreso, y de la integración de los diversos atributos de la mente y del cuerpo en una sola unidad (...)" (p. 43).

Debe consignarse que la noción de progreso no nace simultáneamente al calor del debate teórico que implicó al humanismo renacentista emergente; más bien tiene su génesis en las posturas de importantes figuras del Siglo de las Luces, como es el caso de Nicolás de Condorcet (1743-1794), quien formula y divulga el credo progresista a través de su obra Boceto de un cuadro histórico de los progresos del espiritu humano (1795).

No sucede lo mismo con la categoría "dignidad humana", sobre la cual se tienen ya importantes antecedentes en el Discurso sobre la dignidad del hombre (1486), del renacentista Giovanni Pico della Mirandola, que Ernst Cassirer califica como el "Manifiesto del Renacimiento". Sobre la "dignidad humana" se registran también aportes decisivos por parte del filósofo ilustrado Enmanuel Kant (1983); en su libro Fundamentación de la metafisica de las costumbres se sientan los principios ontológicos, lógicos y éticos de la dignidad humana, basándola en el principio de autonomía racional del hombre y la consideración de su valor como un fin en sí mismo y nunca como un medio al que se le asigna un precio (Kant, 1983, p. 92).

Con Kant asistimos al paradigma de filósofo que argumenta una filosofía y una ética cabalmente antropocéntrica. Su ética tiene un carácter muy abstracto y formal, a espalda del mundo de las emociones y los sentimientos humanos. Serias objeciones se hacen a su ética racionalista, centradas fundamentalmente en su visión antropocéntrica. Frente a esta concepción se empinan las reflexiones de un pensador que considera insuficiente la filosofía moral kantiana de cara a la civilización tecnológica. Dicho pensador es el filósofo Hans Jonas, quien pone en entredicho el ethos moderno tal como lo conceptúa E. Kant.

En conformidad con las ideas joneanas, la ética kantiana deviene incapaz para dotar de sentido la vida y el quehacer humanos dentro del contexto de la tecnociencia actual. Tal planteamiento lo efectúa en las postrimerías del siglo pasado. En su propuesta crítica resalta su controversial planteamiento de que 
la naturaleza está revestida de dignidad 5 , por lo que en adelante habrá de hablarse ya de una dignidad natural; condición que lleva a otra conclusión no menos importante: que deben postularse derechos naturales (Jonas, 1995, pp. 34, 35).

Para Jonas, por consiguiente, ya no debemos limitarnos a postular la existencia de dignidad y de derechos humanos, sino que deberíamos atribuirlos además a la naturaleza. Como puede colegirse, el humanismo es una categoría dinámica y compleja que, en su desarrollo lógico-histórico pasa por muchos recovecos y, parecido a un río, acoge múltiples afluentes, unos con aguas cristalinas, otros con aguas turbias. Hay una evolución de los conceptos, dentro de los cuales hay múltiples determinaciones, algunos cobran o pierden vigencia, según la marcha de los acontecimientos humanos.

Tengo para mí que el agotamiento del relato humanístico luce inevitable de conformidad con la marcha de los acontecimientos en el seno de la postmodernidad o sociedad líquida. Lo mismo observo en lo tocante a las disciplinas humanísticas. El individualismo y el consumismo característicos de nuestra época, impulsados por el mercado globalizado y estimulados por los indetenibles adelantos de la ciencia y la tecnología, no permiten colocar al ser humano y a las disciplinas humanísticas en un sitial de preponderancia. Durante varios siglos, el ser

5. En su obra, El principio de responsabilidad. Ensayo de una ética para la civilización tecnológica (1979), Jonas realiza una de las primeras reflexiones filosóficas y éticas sobre temas biológicos y ecológicos, colocando sobre el tapete la responsabilidad del ser humano de cara a la conservación y cuidado de la biodiversidad y el planeta en sentido general. Coloca las bases de lo que denomina Ética Planetaria, por lo que puede ser considerado uno de los pioneros en el establecimiento de un nuevo apartado filosófico (ecofilosofía o filosofía ecológica) y para una subrama de la ética (la ética medioambiental o ecoética). Uno de los aspectos más llamativo de sus reflexiones teóricas es el concerniente a la dignidad de la naturaleza, donde encontramos planteamientos como el siguiente: "decimos que la comunidad de destino del hombre y la naturaleza, comunidad recién descubierta en el peligro, nos hace redescubrir la dignidad de la naturaleza y nos llama a preservar, más allá de lo puramente utilitario, su integridad" (Jonas, 1995, 228). humano se constituyó en centro de todo. Como observa Manuel Matos Moquete (2018) "el homo sapiens fue colocado en el centro del universo", punto único y privilegiado alrededor del cual todo giraba. El libro del Génesis lo concibió así y lo repitió millones de veces. Y la ciencia y filosofía del siglo XVII vinieron a ratificar dicho señorío, de manos de Francis Bacon y René Descartes. En efecto, con el creer, el saber y el poder cantando a coro, el hombre se autoconcibió dueño absoluto y señor de la naturaleza. Con la gravedad de que el poder que la tecnociencia ha puesto hoy en manos humanas resulta ilimitado y fuente de riesgo permanente. De ahí que Jonas (1995) advierta:

Solamente con la supremacía del pensamiento y con el poder de la civilización técnica posibilitada por él, una forma de vida, "el hombre", se ha colocado en situación de poner en peligro a todas las demás formas de vida $y$, con ellas, a sí mismo.

En el hombre la naturaleza se ha perturbado a sí misma, y sólo en la capacidad moral de aquél -cuyo origen también está en la naturaleza- se abre la incierta posibilidad de un ajuste de las convulsiones provocadas en su homeostasis (pp. 229, 230).

Así pues, con tanto poder acumulado los seres humanos debemos visualizarnos de forma más humilde o menos arrogante, como opción de ir creando las condiciones que posibiliten vivir en forma más amigable con el mundo natural y el resto de los seres vivos.

Manuel Matos Moquete constata precisamente cómo en el discurrir del siglo xx la confianza del ser humano en sí mismo fue disminuyendo, ganando cada vez más terreno el escepticismo. De ahí que "La idea de progreso humano fue menguando, a pesar de los avances en la solución de los problemas materiales, de educación y de salud. A pesar del avance de las ciencias y la tecnología" (Matos Moquete, 2018, p. 38). 


\section{Emergencia del relato antihumanístico: la tec- nología como nueva panacea}

Ya se ha visto, cómo ha ido en declive la narración humanística. Frente a su eclipse emerge otra narrativa, la del relato antihumanístico. Matos Moquete (2018) constata que en la actualidad existen importantes intelectuales que reúnen todas las condiciones ostentadas por los humanistas ${ }^{6}$ de antańo, pero:

no se tienen como grandes humanistas. Me quedo con el ejemplo de Noam Chomsky, gran lingüista, gran pensador, gran conocedor de la biología, la psicología, la inteligencia artificial, etc. (...).

Entonces, ¿por qué Chomsky no es presentado habitualmente como el gran humanista? (p. 42).

Nuestro autor reconoce que en la medida en que valoremos, como demanda social del momento, los enormes conocimientos especializados, en esa misma medida nos vamos a distanciar del ideal humanístico.

Ahondando en torno a la problemática, el semiólogo argumenta cómo a partir del predominio de la imagen se va operando la ausencia de sistema de pensamiento y de valores espirituales. Y así Matos Moquete (2018) explica:

La imagen se multiplica por doquier como expresión de cultura y comunicación (...). Pero la imagen ¿qué dice sin la lengua? La imagen dice tanto que no dice nada. No tiene direccionalidad en el mensaje. Es el reino del ver y el mirar; el de la percepción analógica,

6. Uno de ellos tiene la particularidad de ser considerado como el "último representante del humanismo universal" (...), por su vasta cultura enciclopédica y sus grandes aportes al conocimiento de la cultura medieval a través de la ficción y de estudios científicos" (Matos, 2018, p. 39). El autor hace alusión a Umberto Eco, semiólogo, crítico literario y pensador italiano fallecido en el 2016. no lógica. La imagen no habla, deja entender, entrever. El sentido ha perdido, con la imagen, su dominio (p. 44).

Tal estado de cosas lleva nuestro autor a sentenciar: "La publicidad es el gran filósofo de la época. Es por donde y desde donde se proyectan los grandes mensajes que nos importan" (p. 46).

Por supuesto, todo ha venido a estar al servicio del mercado y sus finalidades, no solo la ciencia y la tecnología, sino también la política y las instituciones religiosas y académicas. Dentro de este contexto global, las humanidades y las ciencias sociales han quedado subordinadas a la lógica del mercado, reproduciendo tanto en sus currículos y su quehacer el modelo epistemológico, ético y pedagógico del homo economicus, que hoy equivale a decir homo technologicus.

Pero si convenimos en que la publicidad ha venido a suplantar a la filosofía, entonces puede concluirse que hoy la tecnología se erige en "la última panacea", en "El arca de Noé de estos tiempos. Se nos promete que con conocer y manejar la tecnología y el idioma inglés ya estamos salvos. Ese es el gran currículo de la época” (Matos, 2018, p. 50).

Para Carlos García Gual (2018) lo anterior encierra un gran empobrecimiento, dado que el ser humano tiene unas capacidades imaginativas, de memoria y de entendimiento, que se abren con la cultura; pero eso no les interesa a quienes nos gobiernan. Está demostrado que a los gobernantes no les ocupa la formación cultural de la gente.

Publicidad y tecnología al servicio del consumismo, a través de una demanda inducida, donde todo -cultura e intelecto incluidos- se convierte en mercancía, en producto de desecho. En nuestra época se impone de esta suerte una cultura del reciclaje, peor aún: del despilfarro. La situación no puede tornarse más grave para la pervivencia del relato humanístico. De ahí que Matos Moquete se cuestione sobre qué puede hacer el humanismo 
en un contexto sociocultural como el previamente señalado, donde no hay mensajes claros, sin ideas, valores, discursos, sin textos, sin lengua.

Todo esto coincide con la llamada "muerte de las ideologías”, dando lugar a una sociedad en que predomina lo sensual, casual e instantáneo. El autor hace referencia a Zigmunt Bauman, quien ha intentado explicar la vida y la sociedad actuales en su reconocida obra Modernidad líquida (2002). Con dicha metáfora Bauman describe y evalúa los rasgos esenciales de la sociedad globalizada, matizada por una economía de servicios y de tecnología informática y comunicacional; así distingue entre "modernidad sólida" asociada al capitalismo o modernidad clásica, y "modernidad líquida” emparentada con los tiempos o estilos de vida postmodernos, a partir de la segunda mitad del siglo xx. Durante esas cinco décadas los valores de la cultura tradicional experimentan una rotunda transformación. Ya nada permanecerá firme o estable en lo tocante a lo moral, social y político-económico, predominando lo instantáneo, lo inestable, lo inmediato. De ahí el referido consumismo exacerbado y la tendencia generalizada al esnobismo. Como efecto, la identidad personal en el mundo líquido es totalmente movediza y fragmentaria. En realidad, más que hablar de identidad, habría de hablarse de identidades, ya que el fenómeno de las migraciones impone cambios sin cesar en el ethos y en las formas de vida de los individuos y las sociedades.

Frente a tal contexto, Matos Moquete (2018) describe y deplora:

la deshumanización de nuestra sociedad. (...) la ausencia de propósitos e ideales. El ser humano ha dejado de ser sí mismo, de contarse para sí. De verse en su belleza y esplendor o en su fealdad.

Estamos reducidos a la irrisión, al escarnio, a la cultura del entretenimiento. La fiesta, el juego en general, los matatiempos o los ganatiempos, son la expresión de la situación dramática del ser humano, que ya no puede esperar nada de la historia y ante el absurdo (...) se entretiene indefinidamente con palabrerías, tecnologías, y trucos de las mil maneras, entre ellos el gran consumo, sello característico de esta sociedad (pp. 46, 47).

El análisis anterior conduce a Matos Moquete a demandar una narratología nueva, portador de proyectos y utopías nuevos, que den sentido y entusiasmen a vivir de un modo diferente. En este nuevo relato se podrían integrar elementos positivos del legado renacentista e ilustrado, combinado con aspiraciones y valoraciones del modelo societario y cultural vigente en la actualidad. Conjugar los aspectos positivos de la cultura del pasado y los aportes positivos de la cultura actual, para recobrar la estabilidad perdida y así superar la actual situación de incertidumbre y su consecuente falta de ideales.

\section{Irrupción del posthumanismo y el transhu- manismo: disenso crítico de Manuel Matos Moquete}

Frente a la ausencia de un discurso humanístico capaz de hablarle a la humanidad presente y de dotar de sentido la vida y el pensar en provecho de la humanidad actual, nuestro autor no se rinde y, "lanza en ristre", declara que se requiere de la creación de otras propuestas en esa dirección, de un nuevo relato que esté en capacidad de contar toda la historia; pero no está de acuerdo con un regreso sin más a los orígenes, más bien se trata de construir. En suma, Matos Moquete (2018) plantea la urgencia de:

un relato total del humanismo, un relato abierto e inconcluso como el humanismo helénico y el renacentista. Un relato que conserve el núcleo ideológico de aquellos relatos, pero con una nueva narratología: nuevas acciones, nuevos tiempos, nuevos personajes y nuevos valores (pp. 51, 52).

Para el autor el proyecto humanístico es hoy más necesario que nunca, no solo por el modelo actual 
de sociedad negadora de los valores del humanismo, sino además porque en la actualidad están en plena gestación nuevos relatos que, como el posthumanismo y el transhumanismo, anuncian el fin del ser humano y del humanismo.

Como exponente inicial del movimiento posthumanista se destaca el filósofo alemán Peter Sloterkijk, quien emplea dicho vocablo para referirse a la etapa nueva por la que atraviesa el humanismo tradicional. El hito inicial de esta doctrina data del 1999, cuando dicho pensador retó en carta abierta a Jürgen Habermas, su antiguo maestro; Habermas lo acusó de ser autor de una propuesta para cría de seres humanos. Si bien Habermas no consintió discutir con el que fue su discípulo, sí lo hicieron algunos filósofos, con lo cual las ideas de Sloterkijk ganaron amplia cobertura. Pero ha sido su conferencia "Normas para el parque humano" (2000), la que le situaría en el centro del debate filosófico europeo y mundial, al dejar planteado los grandes problemas filosóficos del futuro: la biopolítica, la tecnología genética, la formación de los cuerpos y de las mentes.

El autor tiene reservado un sitial importante en cuanto al surgimiento del posthumanismo, al proclamar el fracaso y fin del humanismo tradicional ${ }^{7}$, causado por su imposibilidad de dar sostén al sistema educativo actual y servir de base al proceso civilizatorio de corte occidental. En tal sentido, en opinión de Sloterkiji el modelo humanístico resulta incapaz de informar y formar a las personas en los temas relacionados con "las nuevas formas de relaciones humanas y las transformaciones del espacio íntimo, privado y de los espacios públicos a partir de la revolución digital" (Chavarría, 2013 citado por Matos Moquete, 2018, p. 9).

\footnotetext{
7. Los humanistas están vinculados, según este autor, a las funciones y logísticas del Estado nación. Con las nuevas realidades en que nos instala la sociedad globalizada e interconectada, hecha posible por la moderna tecnología de la información y la comunicación, el humanismo pierde vigencia y capacidad discursiva para dotar de sentido la nueva realidad mundial, la cual no puede abordarse ya desde los estrechos marcos del Estado nacional.
}

Manuel Matos Moquete efectúa la recepción del posthumanismo a través de las tesis básicas del "Manifiesto Posthumanista", proclamado por Robert Pepperell ${ }^{8}$ en 1995. Cita las dos primeras tesis del Manifiesto:

1. Ya es claro que los humanos hemos dejado de ser las "cosas" más importantes del universo. Lo anterior es algo que los humanistas no han podido entender aún.

2. Todo el progreso tecnológico de la sociedad humana se articula hacia la transformación de la especie humana como es entendida ${ }^{9}$ en estos momentos (Pepperell, 2012 citado en Matos Moquete, 2018, p. 53).

Para el ensayista dominicano, en el discurso posthumanista de Pepperell se alienta un fuerte pathos utópico, advirtiéndose un hilo de continuidad entre el humanismo renacentista y las aspiraciones de los autores posthumanistas, ansiosos por superar al ser humano que hemos conocido hasta hoy. Asegura que temas tan actuales de la bioingeniería y la biomedicina, como las células embrionarias, la fecundación in vitro, la clonación, el empleo de la píldora y otros recursos anticonceptivos, no son ajenos a la utopía ya abrazada por el humanismo renacentista. Para el semiólogo, los cambios radicales en marcha no simplemente afectarán, sino "más bien cambiarían los valores humanos, y aún más, la naturaleza humana” (Matos Moquete, 2018, p. 52).

8. Doctor en Arte por la Universidad de Gales, Robert Pepperell (Londres, 1963) se ha dado a conocer por una variedad de artículos muy polémicos, especialmente por dicho Manifiesto, un anexo de su obra The Posthuman Condition (1995).

9. Precisamente, el ser humano deja de ser lo que hasta ahora ha sido debido a que, como expresa la tesis número siete del Manifiesto Posthumanista, "En la era posthumanista las máquinas dejarán de ser máquinas"; o las tesis doce, trece y catorce, respectivamente, en las cuales Pepperell (1995) postula: "Las máquinas complejas son una forma de vida emergente", "Una máquina compleja es una máquina cuyos funcionamientos no podemos entender a cabalidad", "Así como las computadoras se desarrollan para parecerse más a los humanos, los humanos se desarrollan para parecerse más a las computadoras" (s/p). 
Comparte con el posthumanismo el señalamiento de que el paradigma humanista tradicional acusa una grave crisis, lo que demanda repensarlo, incluyendo la condición humana misma. Empero, está de acuerdo con "el relanzamiento del humanismo, no en su postergación". Humanista coherente, el pensador está convencido de que el ser humano es un hecho cultural, el cual es creado por el mismo ser humano. En tal sentido, Matos Moquete (2018) declara:

Nadie, ni siquiera Dios lo creó cuando según el Libro del Génesis dijo: "Hagamos al hombre a nuestra imagen, conforme a nuestra semejanza" (...).

El ser humano ha sido obra del ser humano en un largo y tortuoso proceso de evolución, sobrevivencia y adaptación al medio, armado de dos recursos que le son congénitos: el lenguaje y el razonamiento (p. 54).

En relación con estos planteamientos, cabe traer a colación algunos señalamientos realizados por el filósofo vasco José Ignacio Galparsoro, en el sentido de que el hombre es un resultado más del ciego proceso seguido por la evolución, "el único animal que parece haber comprendido el mecanismo que le ha llevado hasta su presente como especie" (Galparsoro, 2014, p. 154). Para él, el hombre, gracias a su tecnología, podría intervenir en el proceso evolutivo para tratar de "mejorar" sus prestaciones biológicas atravesando de este modo el umbral de la humanidad con el propósito de lograr una condición "transhumana" o "posthumana". Al respecto, Galparsoro (2014) asegura:

Se están empezando a abrir las puertas para que la razón (un producto de la selección natural) pueda actuar de manera consciente sobre el mecanismo evolutivo. Se plantea así una cuestión, inquietante para muchos: ¿ $\mathrm{Se}$ puede cambiar la naturaleza humana (incluyendo la naturaleza humana) de manera consciente? A la que sigue otra: ¿¿Si se puede, se debe hacer? (p. 154).
Para Matos Moquete (2018) las formulaciones del relato posthumanista, en cuanto a que el ser humano actual está siendo transformado radicalmente, puede interpretarse como algo ficticio: "Estamos aquí ante una utopía, ante una ficción humana que nada tiene de extraño. Una ficción tan humana como son los mitos y las ciencias, los cuales son maravillosas creaciones humanas" (p. 55).

Para el pensador crítico, la ciencia y la tecnología podrían modificar la condición humana y, por ejemplo, transformarla en extraterrestre; pero eso no significa que por ello se pierda la esencia de lo humano. Del mismo modo, el trasplante de órganos, la reproducción in vitro o la clonación no escapan del dominio de la capacidad humana. Por lo que Matos Moquete (2018) se pregunta:

¿Desde cuándo el ser humano se reduce al componente biológico? (...). ¿ Desde cuándo se le ha puesto límite a la condición humana, a su evolución, a su desarrollo, hasta poder decir que a partir de tal cambio o de tal hecho se deja de ser humano y que debemos de considerar como no humano lo que ahora somos, un ahora en constante movimiento y transformación, para dar nacimiento a otro ser que se denominaría posthumano? (p. 56).

Tomando en cuenta el tema de "la naturaleza humana”, dos pensadores impugnan los postulados transhumanistas; se trata de Francis Fukuyama y Jürgen Habermas. Para el primero la biotecnología representa una amenaza significativa, pues hace posible la alteración de la naturaleza humana. Fukuyama (2002) expresa: "Una tecnología lo bastante poderosa para transformar aquello que somos tendrá, posiblemente, consecuencias nocivas para la democracia liberal y para la naturaleza de la propia política" (p. 23).

Galparsoro (2014) pone de relieve la concordancia existente entre Habermas y Fukuyama, en el sentido de que los seres humanos somos depositarios de una "esencia" humana que deberá preservarse 
siempre. Ambos autores se caracterizan por su actitud de rechazo contra las biotecnologías aplicadas al ser humano, basándose en motivaciones políticas y morales. Argumentando sobre el tema, Habermas constata lo siguiente:

El avance de las biociencias y el desarrollo de las biotecnologías no sólo amplían las posibilidades de acción ya conocidas, sino que posibilitan un nuevo tipo de intervención. Lo que hasta ahora estaba "dado" como naturaleza orgánica y como mucho podía "cultivarse" entra ahora en el ámbito de la intervención orientada a objetivos (...). Se desvanece la frontera entre la naturaleza que "somos" y la dotación orgánica que nos "damos" (Habermas, 2002 citado en Garpalsoro, 2014, p. 161).

En esta perspectiva, Galparsoro (2014, p. 162) comenta:

Aquí Habermas señala una frontera que no hay que traspasar: las personas no son cosas y las cosas no son personas. La alteridad no humana no debe contaminar al hombre porque la condición del hombre es intocable. Toda posibilidad de "mejora" es descartada porque ello significaría que se está reificando al hombre. Y esto es, para él, éticamente inaceptable.

Importa consignar aquí un juicio de valor externado por Galparsoro en torno a lo sostenido por Habermas:

Los argumentos de Habermas son fundamentalmente ideológicos: la posibilidad de intervenir en el genoma humano es una novedad que podría ser aprovechada por el "mercado". Este no buscaría más que su propio beneficio, sin importarle para nada la eventual violación de los límites de lo humano. Para evitar que las biociencias movidas por intereses mercantiles se desboquen, es preciso intervenir (Galparsoro, 2014, p. 162).
Pero ¿cuál sería finalmente la posición habermasiana de cara al transhumanismo? Desde la óptica del filósofo vasco José Ignacio Galparsoro, dicha postura está bien clara: "de entrada, no. Y es que la eugenesia "activa" defendida por los transhumanistas convertiría a la persona en cosa" (Galparsoro, 2014, p. 162).

Por otra parte, Matos Moquete se propone argumentar que la búsqueda de perfección y un mayor bienestar en provecho de los seres humanos, no cambia cualitativamente lo que somos, convirtiéndonos en posthumanos o transhumanos. Para ello nos introduce en un tema que incita a una profunda reflexión. Me refiero a la función reproductora del organismo humano y cómo la sexualidad, las relaciones sociales, etc. estuvieron durante siglos al servicio de la reproducción. Matos Moquete (2018) argumenta y luego se interroga: "La sexualidad fue concebida como un medio para la reproducción humana. Así pensaban la ciencia, la moral y la religión ¿Y ahora qué tenemos?” (p. 60).

Se cuestiona qué sería de la humanidad, y de nuestro propio planeta, si la función vital de las relaciones sexuales se hubiera mantenido en conformidad con lo dictado por una tradición milenaria, esto es: servir fundamentalmente a la causa de la multiplicación de los seres humanos, emulando el "creced y multiplicaos" del libro del Génesis.

Como Baudrillard (2002) explica:

En primer lugar, el sexo fue liberado de la reproducción; hoy la reproducción es la que está liberada del sexo, a través de modos de reproducción asexuales y tecnológicos como la inseminación artificial o la clonación de todo el cuerpo. Es también una liberación (...). Hemos sido sexualmente liberados, y ahora nos encontramos liberados del sexo, es decir, virtualmente liberados de la función sexual (Citado por Matos Moquete, 2018, p. $61)$. 
Matos Moquete (2018) lo expresa llanamente:

hoy para tener hijos no es necesario hacer el amor. La fecundación in vitro permite que el semen sea depositado en el vientre de la mujer sin necesidad de que entre ella el hombre medien relaciones sexuales.

No existen, pues, gracias a las ciencias, vinculación directa entre la sexualidad y la reproducción. ¿Es eso contrario a la naturaleza humana? ¿Somos por eso inhumanos, posthumanos, transhumanos? Creemos que no (p. 61).

En este apartado el autor regresa a François Rebelais, importante autor renacentista que aspiraba a la consecución de "un ser humano absoluto y perfecto en todo, en el cuerpo y en el alma, en su naturaleza, en sus valores, en todo su saber". Estos conceptos sirven de argumento al filólogo dominicano para establecer un vínculo importante con las tesis centrales posthumanistas. Su conclusión es que las aspiraciones por un ser humano cada vez más perfecto, ayudado por la ciencia y la tecnología, ya estaba contemplado y sugerido en el humanismo proyectado por el mencionado renancentista Rebelais, al postular la búsqueda de lo absoluto y lo perfecto en esta vida terrenal y no en esferas celestiales fuera de este mundo.

Así pues, Matos Moquete ve en las características de este "nuevo ser" descrito por los posthumanistas, al mismo ser humano dibujado por F. Rebelais (1532) en carta a su hijo ${ }^{10}$ durante el Renacimiento,

10. Renacentista del siglo XVI, François Rebelais escribió la novela titulada Pantagruel, basándose en las antiguas historias tejidas alrededor del gigante Gargantúa (padre) y Pantagruel (hijo). A través de esta obra cómica Rebelais mezcla gigantes y farsantes, borrachos y cretinos, de los cuales se vale para dirigir una crítica de carácter humanístico renacentista al quehacer pedagógico imperante en su tiempo, encerrado aún en los férreos moldes del mundo medieval. En el capítulo VIII del libro de marras aparecen los contenidos de la Carta de Gargantúa a su hijo, donde exhorta a una vida virtuosa, perfecta y de culto a la libertad. en la cual expresa a su vástago el ansia de procurar una vida absolutamente perfecta. En tal sentido, a lo que se asiste con el proyecto del posthumanismo, es a un cumplimiento de lo ya prefigurado por Rebelais.

\section{La cibernética y la inteligencia artificial. Su im- pacto sobre el relato humanístico}

El capítulo 3 de Narratividad del saber humanistico, titulado "Ser humano y cibernética", el autor lo dedica a evaluar críticamente el impacto ejercido por la cibernética y la inteligencia artificial sobre la narración humanística. Con ambas vertientes, prohijadas por la tecnología contemporánea, la humanidad deviene instalada en el reino de las máquinas inteligentes. Para Matos Moquete (2018) importa mucho dar seguimiento al tema de la cibernética "puesto que es el pensamiento dominante en esta época, del cual en gran medida han surgido los planteamientos posthumanistas y transhumanistas" (pp. 64, 65).

En esta temática nuestro autor sigue las reflexiones trazadas por David Auriel en su libro La cibernética y lo humano (1966). Distingue tres características o elementos que permiten reconocer lo cibernético, como son: "un pensamiento dominado", "el trabajo intelectual de las máquinas", "el pensamiento claro" y que "toda reflexión puede ser mecanizada precisamente porque no implica nada humano" (David Auriel, citado por Matos Moquete 2018, p. 64).

Pero la conclusión fundamental en todo esto es que a través de la cibernética quedamos instalados en la regulación y mecanización del pensamiento, gracias a la invención de las máquinas pensantes, las cuales gozan de cierta autonomía con respecto a su creador, el ser humano. En efecto, el hombre estaría bajo su dominio, a ellas tendría que plegarse y obedecer sin más. Y es aquí donde nuestro intelectual crítico capta el momento de emergencia de una nueva corriente dentro del pensamiento humano, lo cual conduce a una ruptura en el proyecto humanístico, pues para Matos Moquete (2018) 
"La informática y la robótica (...), creación del ser humano, partes de la cibernética, han venido a reforzar ese alejamiento, sobre todo porque han hecho descender ese distanciamiento al nivel de las creencias y el consumo populares" (p. 66).

Para nuestro autor, el Cyborg o robot constituye el nuevo invitado de la época, que invade la vida cotidiana, los hogares, las fábricas y las oficinas. Así, frente a quienes defienden que el cíborg es un ser humano mejorado por la inteligencia artificial, el ensayista lo concibe, "como una criatura mixta, la cual reúne elementos orgánicos y elementos mecánicos, (...) un recurso inventado por los humanos para potenciar sus energías y sus posibilidades, incluyendo su pensamiento" (Matos Moquete, 2018, pp. 66. 67).

De acuerdo al intelectual, el denominado "pensamiento informático" busca funcionar como racionalidad filosófica; sin embargo, el estilo de pensar informático es en realidad un pensamiento humano y no de las máquinas, ya que estas no piensan, y si lo hicieran es en función de un pensamiento programado, formulado por humanos. Pero también en este apartado en que reflexiona en torno a la mecanización e informatización, Matos Moquete concluye reiterando una tesis ya dilucidada: que todo esto no es sino parte del ideal humano por alcanzar lo absoluto y la perfección, parte esencial de la utopía que ya estuvo en la mente del autor renacentista François Rebelais (1494-1553).

En otro orden, el capítulo 3 permite al autor analizar el carácter del pensamiento funcional de nuestro tiempo, que a su juicio conduce a la "mecanización y cosificación de la vida y el pensamiento humanos. ¿Qué significa eso? Que nos vemos, nos percibimos, a través de las cosas, hasta tal punto que nos consideramos cosas" (Matos Moquete, 2018 p. 68).

Lo anterior encierra un grave peligro, si tenemos en cuenta la valoración de la persona humana según los cánones humanísticos. Para el pensamiento funcional: "Valoramos y nos valoramos en función de lo que se posee (...) En las personas $\mathrm{y}$ en las instituciones, el estatus el valor principal. Es decir, la marca que proyectamos. En eso consumimos, como principio y fin, nuestros mejores afanes" (Matos Moquete, 2018, p. 69). El pensador reconoce, no obstante, que "Nunca antes los seres humanos habían desarrollado una conciencia tan firme de sus derechos en todos los espacios sociales" (Matos Moquete, 2018, p. 69).

En realidad, al hombre y la mujer de hoy lo que más interesa es disfrutar de la vida "aquí y ahora", aun sea dentro de un mundo lleno de riesgos permanentes. La creencia de que el bienestar o felicidad se vivirá en una esfera supraterrenal, con posterioridad a la muerte - paraíso prometido por infinidad de religiones-, se deprecia cada vez más en las denominadas sociedades líquidas. Igual suerte ha corrido el sueño marxista en cuanto a la construcción de la utopía socialista. Con la muerte de las ideologías y sus grandes narraciones futuristas, por cuya consecución murieron millones de personas en todo el mundo, las aspiraciones de la gente hoy en día son más prácticas y sencillas, más individuales y a corto plazo, conformándose con satisfacciones modestas casi siempre de corte material. De ahí la conversión del consumismo en una especie de religión actual. Esto conlleva, como lo pone en evidencia nuestro autor, una nueva manera de concebir la vida y la felicidad.

Sin embargo, como se palpa en la obra del humanista dominicano, hoy se asiste a un periodo de la historia humana en la cual están de moda las ideas y sueños de un conjunto de filósofos, científicos y artistas, que militan febrilmente en las filas del posthumanismo y del transhumanismo ${ }^{11}$, proponiendo

11. Siguiendo el orden cronológico de aparición, en primer lugar, se tiene al transhumanismo. El ser narrado aquí -el transhumano- es concebido como un nuevo ser humano que ha superado ya de modo significativo el grado de capacidades físicas y psíquicas de la persona humana actual, situándose en un lugar intermedio entre el humano como tal y el posthumano. Transhumanismo es un concepto acuñado por el inglés Julian Huxley (1887-1975), eminente biólogo que se convirtió en el 
un nuevo tipo de ser humano que tiene como metas alcanzar la inmortalidad y la divinidad. Como señala nuestro ensayista, comentando un breve fragmento del libro Homo Deus Breve historia del mañana, de Yuval Noah Harari, (2016):

La inmortalidad ha sido una gran meta humana. (...) nos orientamos cada vez más hacia una prolongación de la vida humana. La felicidad es un reto acariciado, ya proclamado por Platón. Hemos alcanzado un alto nivel de bienestar, pero no somos felices. Ese es un propósito que la humanidad no abandona. La divinidad implica un dominio del ser humano de su propia imagen y de su propio destino, sin la intervención de fuerzas sobrehumanas. Los hallazgos científicos y los nuevos inventos tecnológicos se dirigen hacia esa meta (citado por Matos Moquete, 2018, pp. 73, 74).

La pregunta que intenta responder Y. N. Harari, profesor de la Universidad de Jerusalén, es “¿Hacia dónde se dirige la raza humana?”. Para Matos Moquete los planteamientos del Harari no son ajenos al tema de la espiritualidad, y hasta incitan hacia un ideal humanista en que ciencia y espiritualidad podrían relacionarse armónicamente.

En lo que resta del tercer capítulo nuestro autor se ocupa en analizar las competencias lingüísticas orales, impresas y digitales, dilucidando cómo

primer Director General de la UNESCO. Dicho autor sostuvo hace casi un siglo: "La especie humana puede, si lo desea, transcenderse a sí misma - no sólo esporádicamente, un individuo aquí de cierta manera, un individuo ahí de otra-, sino en su totalidad, como humanidad. Necesitamos un hombre para esta nueva creencia” (Huxley, 1927, citado en Bostrom, 2011, p. 165). En las postrimerías del siglo xx, el vocablo Transhumanismo llega al medio académico gracias a Nick Bostrom, filósofo suizo experto en inteligencia artificial, que lo define como movimiento cultural, intelectual y científico que afirma el deber moral de mejorar la capacidad física y cognitiva de la especie humana, y de aplicar las nuevas tecnologías al hombre con el fin de eliminar aspectos no deseados, como serían el sufrimiento, la enfermedad, el envejecimiento, etc. inciden en el presente, especialmente en el segmento juvenil. Para el semiólogo, la cultura digital no ha transformado a la naturaleza humana, "No la ha cambiado hasta el punto de hacer que los nativos y los inmigrantes informáticos pertenezcan a especies distintas o a grados de humanidad muy diferentes" (Matos Moquete, 2018, p. 76).

Para el intelectual crítico, el ciberespacio y todo lo que significa el mundo digital, han generado nuevos comportamientos humanos, nuevas maneras de pensar y de vivir, pero tales influencias palpables no convierten sus aportes y creaciones en algo enteramente ajeno y contrario a la naturaleza humana. Se trata más bien de artilugios que vienen a fortalecer la búsqueda ancestral del ser humano de lo absoluto y lo perfecto.

Su opinión es que hoy estamos inmersos en la cultura digital, la cual constituye un nuevo paradigma, el tecnológico. Matos Moquete (2018) nos aclara: "sin embargo, es preciso afirmar que ese paradigma particular, lejos de sustituir al inmenso e inagotable paradigma humano representado por el humanismo, más bien lo amplía y lo consolida" (Matos Moquete, 2018, p. 78).

De acuerdo con los principales impulsores del transhumanismo y el posthumanismo, hacia el 2050 se podrán palpar algunos de sus grandes pronósticos. En tal sentido, se tendrán que cambiar las legislaciones que conocemos actualmente, dado que se hará necesario promulgar derechos cívicos para las máquinas inteligentes. Y no solo eso: será imperativo ampliar los esquemas en los planos ontológico, única forma de reservar a dichas máquinas racionales sus derechos para interactuar con el conjunto de los seres vivos. Son solo algunos de los desafíos lanzados por los autores transhumanistas y posthumanistas.

Al concluir el capítulo tercero de la obra analizada, el semiólogo lleva a cabo un importante estudio acerca del "chateo" como modalidad comunicacional, muy importante hoy en día, para lo cual 
se basa en estudios de casos. Por último, aborda el libro digital y su coexistencia con el libro impreso.

Como se declaró al inicio de ese trabajo, nuestro análisis no tendría como objeto abarcar la totalidad del libro, que consta de nueve capítulos y 313 páginas. El cuarto trata sobre la crítica literaria enfocada como saber humanístico; en el quinto, Matos Moquete aborda la crítica humanística de Pedro Henríquez Ureńa; el capítulo 6 está dedicado al análisis del legado humanístico-político de Max Henríquez Ureña; el séptimo tiene como finalidad adentrarse en el humanismo renacentista de Camila Henríquez Ureña. En el capítulo 8 el autor se ocupa de la vocación humanística y el uso de la lengua en Miguel Antonio Caro; y el último capítulo, el noveno, lo dedica al tratamiento de algunos aspectos vinculados a la gramática y la literatura.

\section{Conclusión}

El libro Narratividad del saber humanistico constituye una especie de "Manifiesto por el Humanismo", una declaración proclamada por alguien que no puede ocultar su perplejidad ante el panorama que vive la humanidad en nuestros días. En esta obra Manuel Matos Moquete aborda los caracteres fundamentales de la narración humanística, efectuando un interesante recorrido a través de sus momentos constitutivos fundamentales. Estamos ante un libro de relevancia, no solo para los especialistas de la amplia gama de disciplinas humanísticas, sino también para los cientistas sociales, los cultivadores de las ciencias naturales y exactas; en fin, para cualquier persona interesada en conocer cuáles son hoy las grandes interrogantes y reflexiones que convergen en el debate sobre el ser humano, las cavilaciones en torno a su presente y su futuro.

Uno de los principales méritos del texto consiste en poner en diálogo diversos saberes humanísticos surgidos a partir de 1960, entre los cuales sobresalen disciplinas entroncadas en el lenguaje (filología, semiótica, crítica literaria, análisis del discurso, retórica, etc.), la filosofía, la pedagogía y las ciencias sociales. Y sin ser biólogo o médico, el autor acoge y examina también importantes hallazgos procedentes de las ciencias biológicas y médicas, así como de otros conocimientos afines. Un diálogo como este solo podría llevarlo a cabo, de manera adecuada, alguien revestido de una amplia formación enciclopédica y una profunda vocación humanística. Afortunadamente, el autor reúne ambas condiciones. Pero, además, en Manuel Matos Moquete habrá de reconocerse una capacidad extraordinaria para tratar de modo claro y sencillo temas de alta complejidad y de elevada abstracción teórica, lo cual logra sin menoscabo del rigor lógico y la claridad conceptual.

Otro mérito indiscutible de Narratividad del saber humanistico reside en el esfuerzo por dotar de sentidos la vida y los sueños, pero también los grandes temores e incertidumbres del ser humano en los tiempos que discurren, caracterizados por la transformación inusitada y acelerada que nos deparan los avances logrados por la ciencia y la tecnología.

Precisamente, son los adelantos alcanzados por las diversas ramas de la biología, la cibernética y la inteligencia artificial los que han provocado el surgimiento de nuevos comportamientos, de nuevas formas culturales y visiones del mundo que, según sus mentores, traspasan ya la frontera de lo netamente humano, dando como resultado a seres ubicados más allá de los confines de la humanidad. A tales seres se les anticipa el nombre de posthumanos $y$ transhumanos. En la presente obra se pone en entredicho muchas de las formulaciones de autores posthumanistas y transhumanistas, planteándose que aunque se esté ante nuevas utopías, no por ello se está en capacidad de argumentar la existencia de nuevos arquetipos o seres paradigmáticos ubicados esencialmente más allá de lo que conocemos como seres humanos.

Los criterios antes expuestos explican las razones por las cuales la obra aquí examinada no debe pasar desapercibida en nuestro entorno científico, humanístico y académico. Formado en Francia, dentro 
de un extenso abanico de disciplinas en el campo de las humanidades, con marcado interés por conocer los grandes aportes y desafíos provenientes de la ciencia y la tecnología, Manuel Matos Moquete se presenta como uno de los intelectuales que adornan el pensamiento crítico y la cultura humanística en la República Dominicana actual.

El presente trabajo pretende contribuir con el debate emprendido por Narratividad del saber bumanistico, libro orientado a provocar hondas reflexiones en torno al puesto y al valor reservado al ser humano, tras los enormes avances promovidos por las ciencias y las tecnologías en los ámbitos de la vida, la salud y el cibermundo.

\section{Referencias}

Baudrillard, J. (2002). La ilusión vital. Buenos Aires, Argentina: Siglo xxI.

Chavarría Alfaro, G. (2013). El posthumanismo y el transhumanismo: transformaciones del concepto de ser humano en la era tecnológica (Informe Final de Investigación, Universidad de Costa Rica). Recuperado de www.kerwa. ucr.ac.cr $>$ bitstream $>$ handle

Fukuyama, F. (2002). El fin del hombre. Consecuencias de la revolución biotecnológica. Barcelona, España: Ediciones B.

Galparsoro, J. I. (2014). Biotecnología y naturaleza humana. La cuestión del posthumanismo. Ágora, 33(1), 153-170. Recuperado de www. usc.es/revistas/index.php/agora/article/ view/1874/1769

García Gual, C. (2 de junio de 2018). Los alumnos pasan mucho tiempo con el móvil. No saben nada. El País. Recuperado de https://elpais.com/elpais/2018/02/05/ eps/1517841144_118374.html

Guadarrama, P. (2012). Pensamiento filosófico latinoamericano. Humanismo, método e historia. Tomo I. Bogotá, Colombia: Editorial Planeta.
Harari Yuval, N. (2016). Homo Deus Breve historia del mañana. Bogotá, Colombia: Editorial Debate.

Hostos, E. M., de. (1939). Falsa alarma. Crisis agrícola. Hostos en Santo Domingo. Ciudad Trujillo: J. R. Vda. García Sucs.

Huxley, J. (1927). En Bostrom, N. (2011). Una historia del pensamiento transhumanista. A history of a transhumanist (Antonio Calleja López (Trad.). Journal of evolution and technology, 14(I). Recuperado de PDF https:// institucional.us.es >revistas $>$ art_7

Jonas, H. (1995). El principio de responsabilidad. Ensayo de una ética para la civilización tecnológica. Barcelona, España: Herder.

Kant, E. (1983). Fundamentación de la metafisica de las costumbres. Madrid, España: Espasa-Calpe.

Matos Moquete, M. (2018). Narratividad del saber humanistico. Santo Domingo, República Dominicana: Soto Editora.

Matos Moquete, M. (2009). Propuestas, valores e ideologias en el discurso político dominicano. Santo Domingo, República Dominicana: Instituto Tecnológico de Santo Domingo (INTEC).

Moro, T., y Campanella, T. (1956). Utopias del renacimiento (Agustín Millares y Agustín Mateo, trads.). México D.F., México: Fondo de Cultura Económica.

Pepperell, R. (1995). "Manifiesto Posthumanista". En The posthuman condition. (Raúl Bravo, trad.). Recuperado de https://cuadrivio.net

Rodríguez Demorizi, E. (Ed.). (1980). Papeles de Pedro F. Bonó. Para la historia de las ideas políticas en Santo Domingo. Barcelona, España: Gráficas M. Pareja.

Xavier de Almeida, M. (2009). Narrativas de una ciencia de la integridad. Citado por Matos Moquete, M. (2018). Narratividad del saber humanistico. Santo Domingo, República Dominicana: Soto Editora. 


\section{Datos de filiación}

Julio Minaya Santos. Profesor Titular de la Universidad Autónoma de Santo Domingo (UASD). Fue Coordinador de Cátedra y director de la Escuela de Filosofía de esta alta casa de estudios, institución donde cursó estudios de licenciatura y especialidad dentro del área filosófica. Doctorado en Filosofía por la Universidad del País Vasco. tesis doctoral titulada "Pedro Francisco Bonó: precursor de la emancipación cultural dominicana. Ideas éticas y político-sociales”. Autor del libro Pedro Francisco Bonó: vida, obra y pensamiento crítico (2014). Líneas de investigación: Pensamiento filosófico dominicano, Pensamiento social dominicano, Pensamiento latinoamericano y caribeńo. 